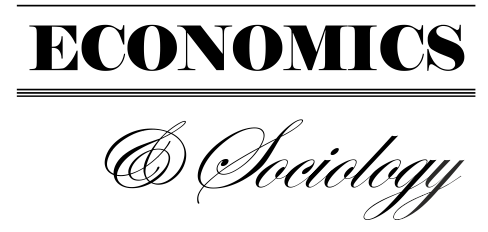

Blázquez-Fernández, C., Cantarero-Prieto, D., Pascual-Sáez, M. (2018). Okun's Law in Selected European Countries (2005-2017): An Age and Gender Analysis. Economics and Sociology, 11(2), 263-274. doi:10.14254/2071-789X.2018/11-2/18

\author{
Carla Blázquez-Fernández, \\ University of Cantabria, \\ Santander, Spain, \\ E-mail:carla.blarquez@unican.es \\ David Cantarero-Prieto, \\ University of Cantabria, \\ Santander, Spain, \\ E-mail:david.cantarero@unican.es
}

\author{
Marta Pascual-Sáez, \\ University of Cantabria, \\ Santander, Spain, \\ E-mail:marta.pascual@unican.es
}

Received: January, 2018

1st Revision: March, 2018

Accepted: May, 2018

DOI: $10.14254 / 2071-$

789X.2018/11-2/18

JEL Classification: E24, E6, F50

\section{OKUN'S LAW IN SELECTED EUROPEAN COUNTRIES (2005-2017): AN AGE AND GENDER ANALYSIS}

\begin{abstract}
In this paper the robustness of the Okun's relationship is tested using data from a group of selected European countries during the period 2005-2017, considering different age cohorts and gender. Four macroareas based on geographic location are also considered: Continental Europe, Nordic countries, Southern Europe, and Anglo-Saxon countries. Two traditional models are applied, the first difference and the 'gap' one. The relevant data for the latter model is constructed from the HodrickPrescott filter. The empirical results indicate that an inverse relationship between unemployment and output holds for the whole sample and subsamples. Besides, it can be highlighted that these countries show smaller output loss associated with higher unemployment. Additionally, our findings suggest that the oldest population tends to be less exposed to the business cycles. Meanwhile, slight differences along countries and macro-areas are found. Therefore, as disparities in productivity growth are showed, different policies are required for each area. Actually, policymakers should design various ways to increase employment opportunities for diverse groups in society (specific coordinated policies for each necessity): those on specific age cohorts, those working in particular economic activities or those living in specific countries or macro-regions.
\end{abstract}

Keywords: Okun's Law; economic growth; unemployment; GDP; European countries.

\title{
Introduction
}

Analysing the relationship between unemployment and output becomes essential due to the differences in productivity growth that could be behind it. It is known that during the last decades, European Union (EU) countries (mainly EU-15 ones) have reduced their disparities regarding income (Gross Domestic Product, GDP). Precisely, common GDP pathways are observed, so it could be said a process of economic convergence has occurred there. Nevertheless, the Great Recession (2007-2009) has affected European labor markets and devastating effects on unemployment have occurred over the last years (Eurostat, 2016). Accordingly, public policies to reduce unemployment rate, and measures to enhance the derived convergence are one of the main issues on the interests of policymakers. 
Consequently, Okun's Law (1962 and 1970) is of great economic interest. It is also a well-known measure of the cost of higher unemployment which supports a negative relationship between unemployment rates changes and real output ones (that is, the welfare costs of business cycles). After that, different empirical studies have tested its implication. Although the results generally support the validity of the abovementioned relationship, in the sense of finding a significantly negative coefficient on cyclical output, empirical findings differ regarding the magnitude of the coefficient that is highly sensitive to several factors (related with the empirical analysis like model specification, econometric method of estimation, sample and period considered). Besides, it is likely that the Okun's Law differs in economic boom and recession periods (Cuaresma, 2003). But also discrepancies are pointed out by other authors (e.g. Ball et al., 2013). Indeed, this topic has rebounded since the Great Recession.

Drawing from this body of literature, the novelty of our paper resides in the study of the Okun relationship using aggregated data over 2005-2017 period when considering an age and gender analysis. What is more, this study is performed, both jointly and separately, for EU-15 countries. The availability of new data allow us to deep in this inquiry (OECD Statistics, 2017). In doing so, we use two traditional approaches, first difference models and the 'gap' one.

Therefore, the main contribution is that we provide new highlights for productivity growth in developed countries. Generally, our main results are threefold. Firstly, we find that the Okun's relationship, despite the fact being the coefficient different by selected European countries, is significant for all macro-areas that we proposed. Secondly, somehow differences by age are appreciated but not gender ones. Thirdly, our findings are consistent between estimates and they are according with recent literature (Lee, 2000). Actually, disparities in productivity growth are showed. Thus, the knowledge of this relationship for every European country is important from the point of view of efficient policy implementation. In addition, the contribution is to shed light from an international perspective, and then to improve that knowledge, when considering as well as individual areas (countries), macro-areas. As a result, comparing with previous contributions, we analyse the link between unemployment rates changes and real output ones for main European countries, using recent data in different specifications and jointly taking into account age and gender factors.

The remainder of the paper is structured as follows. Section 1 presents a brief literature review. Section 2 provides a description of the data and presents the empirical model. Section 3 contains the empirical results. The final section concludes.

\section{Literature review}

Originally, most of the studies which examined Okun's coefficient validity were for the United States (Weber, 1995; or Attfield and Silverstone, 1997), but in recent years this relationship has also been tested for other countries, essentially developed ones due to data availability (Hamia, 2016). To name a few of the latest studies (for a more profuse review, see Perman, Stephan and Tavera (2015) that made a meta-analysis of Okun's Law. They concluded that the correlation between unemployment and GDP movements is close to -0.61 and -1.02.), four classifications are considered regarding studies that tested Okun's Law for Organisation for Economic Co-operation and Development (OECD) members, European countries, groups of developed countries and single-country analysis.

Hence, Lee (2000), Moazzami and Dadgostar (2011), Zanin (2014) and Kargi (2016) tested Okun's Law for OECD countries. Lee (2000) focused on 16 countries during 1955-1996 using both first difference and the 'gap' models. He found after 1970s most countries began to experience a smaller output loss associated with higher unemployment. Additionally, Moazzami and Dadgostar (2011) applied a correction modelling for 13 countries along 1988- 
2007. Their results pointed out that there are significant short and long-run trade-offs between unemployment and output growth appearing discrepancies by countries, whereas Zanin (2014) considered differences with a traditional approach, by age and gender, using data from 19982012 for all OECD countries. The findings highlight that Okun's Law for some sub-groups of the population might be not statistically significant and that the youngest generations are most vulnerable to the business cycle. Besides, Kargi (2016) calculated Okun's coefficient for several countries. This author categorized countries according to its growth rate (as low, normal and high) not founding a consistent unemployment rate for countries with high growth rate, but it is found in countries with lowest growth rate.

As well, Zanin and Marra (2012), Hutengs and Stadtmann (2013), Economou and Psarianos (2016) for European countries confirmed that results are heterogeneous and timevarying. The first one, used penalized regression spline approach for 1960-2009; the following, Ordinary Least Squares (OLS) for 1983-2011 data; and the latest, panel data techniques (and Mundlak (1978) decomposition models) during the period 1993-2014. In addition, in Hutengs and Stadtmann (2013) it is showed that this relationship is strongest for the youngest cohort and becomes smaller for the elderly. Moreover, Economou and Psarianos (2016) provides evidence that the permanent effect of output changes upon unemployment rates is quantitatively larger than the transitory impact.

Thereby, Moosa (1997) or Malley and Molana (2008) for the G7 countries (a group composed by Canada, France, Germany, Italy, Japan, the United Kingdom and the United States). The first one, estimated by OLS and SUR (Seemingly Unrelated Regressions) the Okun's coefficient during 1960-1995. In the second study, 1964-2004 data is used to determine if there exist large differences by country. Besides, Bod'a and Považanová (2015) for PIGS countries (Portugal, Italy, Greece and Spain) by using 1998-2004 data and the Structural Vector Autoregressive framework (SVAR), found that there exist gender asymmetries in Okun's Law. Likewise, Rahman and Mustafa (2017) re-examined the Okun's Law for 13 selected developed countries over 1970-2013. Dynamic OLS estimates and bivariate error-correction model (ECM) show that Okun's Law is quite valid only for USA and South Korea, invalid for Germany, and weaker for the rest countries considered.

Furthermore, there is huge body of literature based on analysis by single countries. For example, Villaverde and Maza (2009) as Melguizo (2017) or Bande and Martín-Román (2017) studied the Spanish case. Their considered different samples and approaches ('gap' specification (1980-2004); Vector Autoregressive framework (VAR) techniques (1985-2013); different panel data technics (1980-2015), respectively). All in all, these authors appreciated that there exist regional disparities in productivity growth. Additionally, Silvapulle, Moosa and Silvapulle (2004) based on a dynamic model using data from the United States, for the postwar period, tested the asymmetry in Okun's Law. Palombi (2017) estimated with instrumental variables approach for Great Britain over the period 1985-2011. Also, Micallef (2016) used different empirical specification for Malta (2000-2016) whereas Zanin (2016) considered a varying-coefficient model for Italy (2005-2014).

\section{Methodological approach}

To begin with, we describe the dataset used in our empirical analysis, considering the group of selected European countries, the sample period, the variables and the sources of information from which we obtained the data. Besides, a descriptive analysis is presented as the first step in order to make tentative conclusions beyond our information.

Our empirical results are based on a complete balance panel data set for the abovementioned EU-15 countries. One of the most important issues is the availability of the 
data. Thus, as we have restricted our analysis to the period that allows us to compare results across countries, we focus on 2005-2017. A period somehow enough for the conclusions here presented. All in all, in order to provide deeper conclusions, future research could be improved when considering all the European countries and interest variables for a longer period of time, or distinguishing by subperiods of time.

We examine the relationship between unemployment and output for EU-15 countries: Austria, Belgium, Denmark, Finland, France, Germany, Greece, Ireland, Italy, Luxembourg, Netherlands, Portugal, Spain, Sweden and the United Kingdom. Furthermore, four macro-areas (based on geographical location) are also considered: (i) Continental Europe: Austria, Belgium, France, Germany, Luxembourg and Netherlands; (ii) Nordic countries: Denmark, Finland and Sweden; (iii) Southern Europe (PIGS): Portugal, Italy, Greece and Spain; and (iv) Anglo-Saxon countries: Ireland and United Kingdom. The latest financial and economic crisis has affected European labor markets, as unemployment rates have considerably increased (Eurostat, 2016). Hence, as analyzing the relationship between unemployment and output becomes these days one of the main issues in Europe.

Our database consists of two main variables: Output or Gross Domestic Product (GDP) at constant prices (2010 base year), and unemployment rates (total, by gender and age cohort). Basic data used in this study is taken from the OECD Statistics (2017). The main variables are described by age group in Table 1 in Appendix.

In order to have a better knowledge of the economic situation and as a first approximation to our econometric estimations, we are going to study how our variables have been changing, both across European countries/macro-areas and over time. Then, Graph 1 plots the cycle differences between output and the total unemployment rate (considering age cohorts) by macro-area whereas Graph 2 shows the distribution of the total unemployment rate disaggregating by sex.

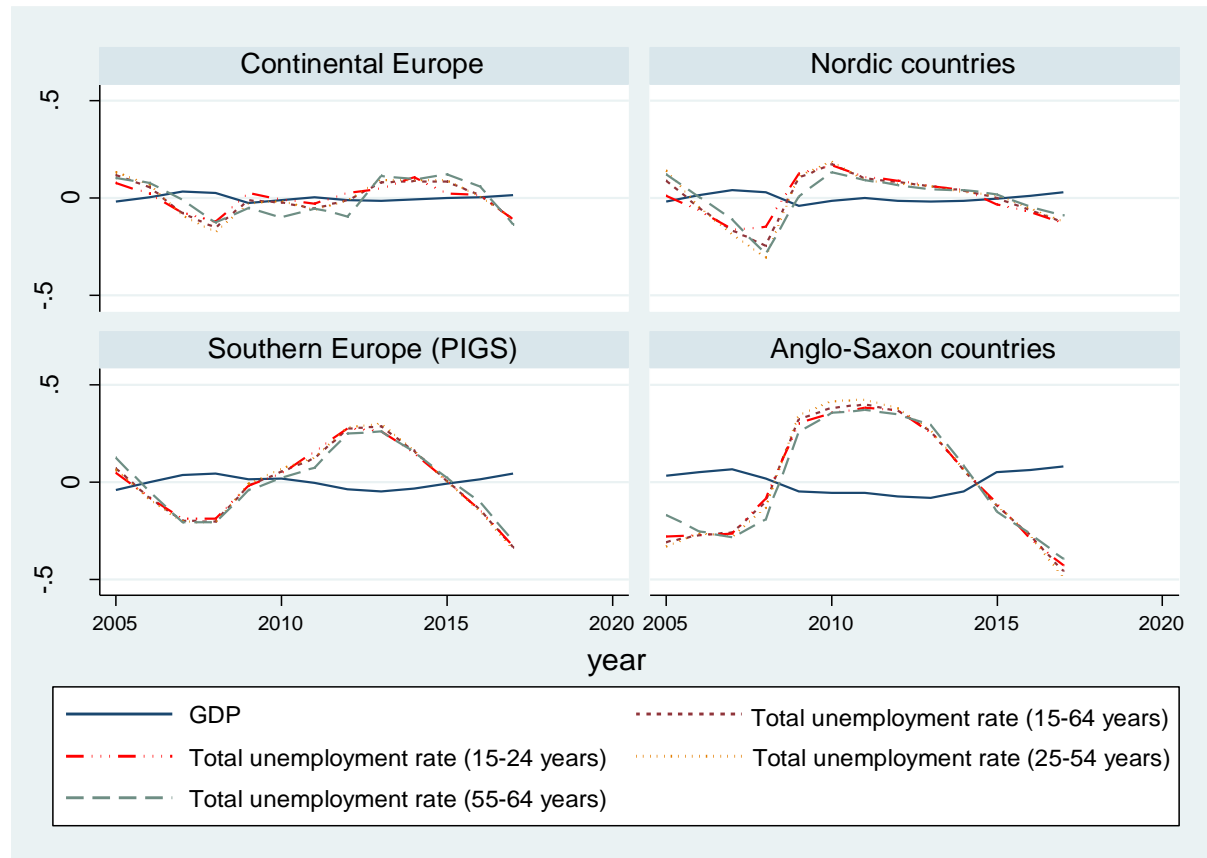

Notes: Continental Europe: Austria, Belgium, France, Germany, Luxembourg, and Netherlands; Nordic countries: Denmark, Finland and Sweden; Southern Europe (PIGS): Portugal, Italy, Greece and Spain; and Anglo-Saxon countries: Ireland and the United Kingdom. Source: Authors' elaboration.

Graph 1. Regional output (GDP) and unemployment rates differences in business cycles from 2005 to 2017

Source: Authors' elaboration. 


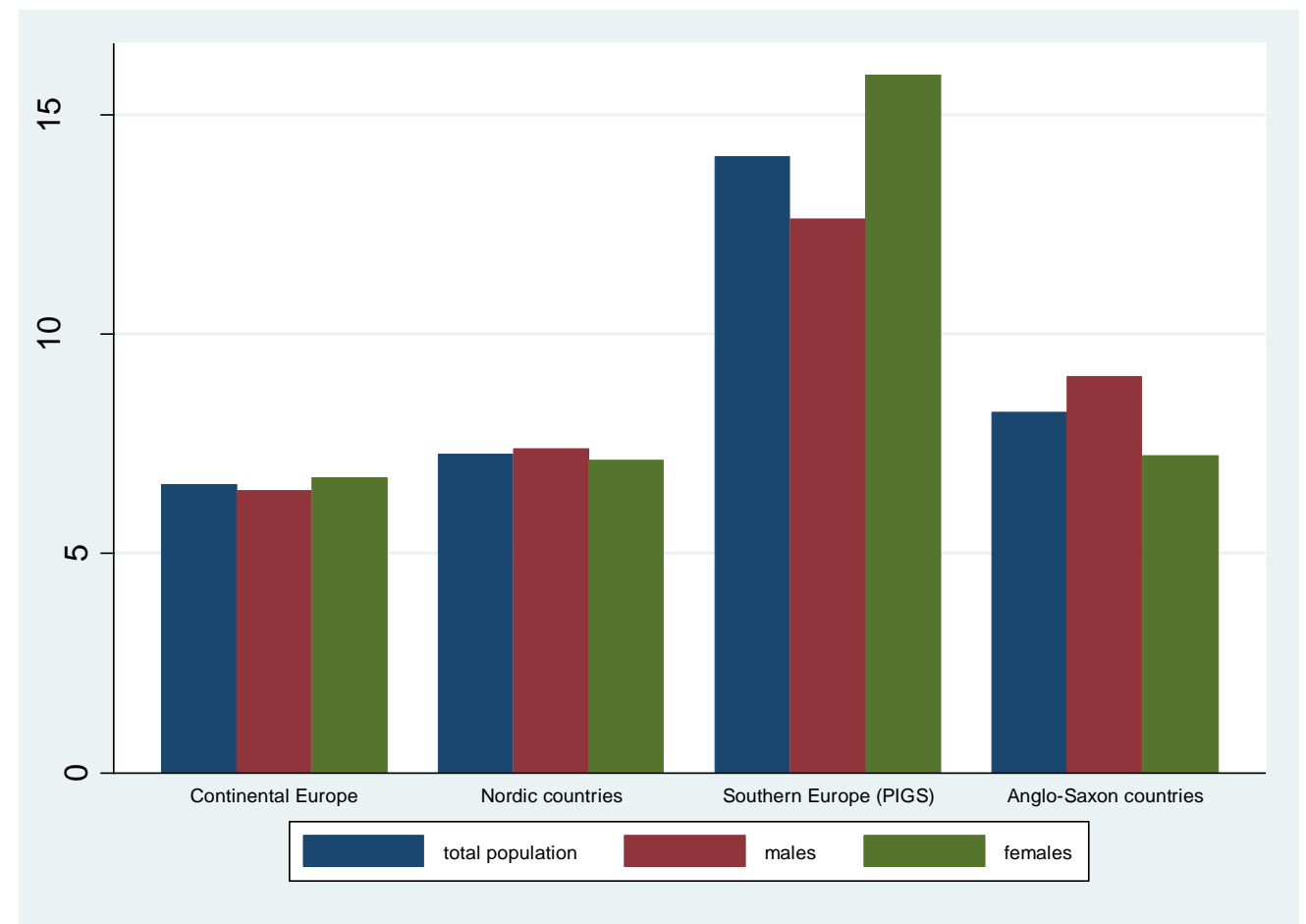

Notes: Continental Europe (1): Austria, Belgium, France, Germany, Luxembourg and Netherlands; Nordic countries (2): Denmark, Finland and Sweden; Southern Europe (PIGS) (3): Portugal, Italy, Greece and Spain; and Anglo-Saxon countries (4): Ireland and United Kingdom.

Graph 2. Distribution of total unemployment rates (mean 2005-2017) by European macro-area and sex

Source: Authors' elaboration.

All that information reflects the regional heterogeneity (across countries) in the relationship between output and unemployment, by regional, age and sex perspectives, and so reinforces the motivation of this study that is the revision of the Okun's law in selected European countries considering an age and gender analysis. Overall, from these Graphs, it is shown a clear difference regarding unemployment rates in the Southern Europe (PIGS) area. In fact, it can be appreciated the highest unemployment rates are due to the higher impact of the crisis in these countries. Besides, when considering age cohort, the largest values are reached by the youngest population one (Rudawska, 2010). Furthermore, slight differences are appreciated also by sex. Females (as young people) appear to be more susceptible to economic downturns than men, as higher rates are observed for this collective. Consequently, the closing of the gender unemployment gap is not appreciated for the selected European countries (Albanesi and Sahin, 2013).

As previously argued, several studies have estimated Okun's Law using static or dynamic specifications. Precisely, two basic approaches are considered in our empirical analysis (Lee, 2000). (i) The differenced model that represents a convenient way to achieve stationary data containing a unit root; and (ii) the 'gap' one that provides inferences on time series behavior over the business cycle.

In the first-difference model, the relationship between the observed real output $\left(\boldsymbol{y}_{\boldsymbol{t}}\right)$ and the observed unemployment rate $\left(\boldsymbol{u}_{\boldsymbol{t}}\right)$ is given by Equation (1):

$$
\Delta y_{t}=\beta_{0}-\beta_{1} \Delta u_{t}+\varepsilon_{t}
$$


where $\Delta$ is a difference operator $\left(\boldsymbol{y}_{\boldsymbol{t}}-\boldsymbol{y}_{\boldsymbol{t}-\mathbf{1}} ; \boldsymbol{u}_{\boldsymbol{t}}-\boldsymbol{u}_{\boldsymbol{t}-\mathbf{1}}\right) ; \boldsymbol{\beta}_{\mathbf{0}}$ is the intercept; $\boldsymbol{\beta}_{\mathbf{1}}$ is the Okun's coefficient (measuring by how much changes in the unemployment rate produce changes in output); and $\varepsilon$ is the disturbance term.

The second approach is related to the notion of the 'gap' between current and equilibrium output and the one in unemployment in the Equation (2):

$$
y_{t}-y_{t}^{*}=\beta_{0}+\beta_{1}\left(u_{t}-u_{t}^{*}\right)+\varepsilon_{t}
$$

where $\boldsymbol{y}_{\boldsymbol{t}}-\boldsymbol{y}_{\boldsymbol{t}}^{*}=\boldsymbol{y}_{\boldsymbol{t}}^{\boldsymbol{c}}$ and $\boldsymbol{u}_{\boldsymbol{t}}-\boldsymbol{u}_{\boldsymbol{t}}^{*}=\boldsymbol{u}_{\boldsymbol{t}}^{\boldsymbol{c}}$. In other words, the difference between the observed and potential (*) output (GDP) and unemployment rates, respectively, captures the cyclical levels of both. Nevertheless, the problem with this model is that there are no observable data on $\boldsymbol{y}_{\boldsymbol{t}}^{*}$ and $\boldsymbol{u}_{\boldsymbol{t}}^{*}$. Thus, they have to be estimated, which means that it is necessary to generate $\boldsymbol{y}_{\boldsymbol{t}}$ and $\boldsymbol{u}_{\boldsymbol{t}}$ trends.

In this study, we just used the Hodrick-Prescott (HP) filter as it is widely useful tool in macroeconomics, which is used to extract a trend component from a time series. Besides, software facilities and the optimality criterion, from which it can be derived, can explain its extensive use. As well, recently De Jong and Sakarya (2016) indicated that consistent with the use of the HP filter by macroeconomists, the cyclical component satisfies weak dependence properties for a wide class of stochastic processes. All these justified its pertinence here.

\section{Conducting research and results}

Before a deeper description of the empirical results from previous estimates, we have performed some preliminary tests in order to reach some conclusions regarding the hypotheses we have made. Mainly, as we are taking into account differences in unemployment (by sex, age, and region), we try to solve differences by them. In doing so, we applied an analysis of variance (so-called, ANOVA). In fact, in Graph 2 it was shown that there are huge differences in total unemployment rates when distinguishing by region or macro-area, being PIGS countries the ones with highest rates and differences. Hence, this macro-area would have a singular space in this study. However, we wonder whether differences may be also explained by sex. To find out it, we fit a regression model (two-factor ANOVA) of the total unemployment rate (1564 years) on region and sex.

The two independent variables in a two-way ANOVA are called factors. The idea is that there are two variables (factors) which affect the dependent variable. Each factor will have two or more levels within it. The degrees of freedom for each factor is one less than the number of levels. Thus, the region term contains three degrees of freedom, and the gender factor contains only one. The null hypotheses for each one are given as follows. (i) The population means the first factor (region), are equal. This is like the one-way ANOVA for the row factor. (ii) The population means the second factor (sex), are alike. Identical to the one-way ANOVA for the column factor. Results highlight that while the null hypothesis regarding there are no significant differences between regions is rejected (ANOVA region2005 $=2.32, \mathrm{p}=0.25>0.05$; ANOVA region2017 $=26.42, \mathrm{p}=0.01<0.05$ ), it is not rejected for $\operatorname{sex}($ ANOVA sex2005 $=1.21, \mathrm{p}=0.35>$ 0.05 ; ANOVA sex2017 $=0.27, \mathrm{p}=0.64>0.05$ ).

Therefore, the following Section does not distinguish results by sex and focus the analyses on differences by the approach, age cohorts, and regions. That is to explain, from our initial question about the robustness of the Okun's Law in selected European countries considering different age cohorts and gender, now we could partially answer, as no sex 
differences are found. Subsequently, in what continues we are going to focus on differences by macro-areas and age cohorts.

In particular, we present our results for estimations of both approaches previously described. Specifically, in Table 2 results for the first-difference model are presented whereas Table 3 contains the equivalents for the 'gap' one. Notwithstanding, the pure interpretation of the Okun's coefficient is different using Equations (1) and (2), as well as with the trend-cycle of the series compared to raw data. Our findings could be synthetically summarized as follows.

Table 2. Okun's Law coefficients: 'First-differenced data', total population

\begin{tabular}{|c|c|c|c|c|c|c|c|c|c|c|c|c|}
\hline \multirow{3}{*}{ Country } & \multicolumn{9}{|c|}{ Age-cohort (years) } & \multirow{2}{*}{\multicolumn{3}{|c|}{$15-64$ years }} \\
\hline & \multicolumn{3}{|c|}{$15-24$} & \multicolumn{3}{|c|}{$25-54$} & \multicolumn{3}{|c|}{$55-64$} & & & \\
\hline & & & $\mathrm{R}^{2}$ & & & $\mathrm{R}^{2}$ & & & $\mathrm{R}^{2}$ & & & $\mathrm{R}^{2}$ \\
\hline Austria & -0.163 & **** & 0.733 & -0.141 & **** & 0.725 & -0.024 & & 0.065 & -0.152 & **** & 0.727 \\
\hline Belgium & -0.094 & **** & 0.512 & -0.089 & * & 0.275 & -0.109 & **** & 0.584 & -0.101 & ** & 0.376 \\
\hline Denmark & -0.113 & ***** & 0.593 & -0.073 & ***** & 0.643 & -0.065 & *** & 0.400 & -0.087 & ***** & 0.641 \\
\hline Finland & -0.306 & **** & 0.762 & -0.262 & **** & 0.804 & -0.248 & *** & 0.339 & -0.305 & **** & 0.784 \\
\hline France & -0.135 & $* * *$ & 0.664 & -0.133 & $* * *$ & 0.526 & -0.086 & *** & 0.486 & -0.137 & *** & 0.604 \\
\hline Germany & -0.323 & **** & 0.641 & -0.322 & **** & 0.603 & -0.100 & & 0.061 & -0.334 & **** & 0.577 \\
\hline Greece & -0.272 & **** & 0.813 & -0.229 & $* * *$ & 0.868 & -0.211 & **** & 0.780 & -0.238 & ***** & 0.878 \\
\hline Ireland & -0.199 & *** & 0.456 & -0.185 & *** & 0.445 & -0.209 & **** & 0.560 & -0.199 & *** & 0.463 \\
\hline Italy & -0.175 & **** & 0.642 & -0.157 & **** & 0.613 & -0.092 & ** & 0.360 & -0.160 & **** & 0.617 \\
\hline Luxembourg & -0.006 & & 0.001 & -0.121 & & 0.214 & 0.010 & & 0.008 & -0.122 & & 0.194 \\
\hline Netherlands & -0.091 & $* * *$ & 0.527 & -0.077 & $* * *$ & 0.678 & -0.044 & & 0.113 & -0.086 & $* * *$ & 0.590 \\
\hline Portugal & -0.120 & ***** & 0.592 & -0.099 & * & 0.478 & -0.115 & "** & 0.462 & -0.111 & **** & 0.526 \\
\hline Spain & -0.117 & **** & 0.554 & -0.105 & $* * *$ & 0.553 & -0.127 & **** & 0.664 & -0.111 & **** & 0.562 \\
\hline Sweden & -0.274 & **** & 0.673 & -0.166 & ** & 0.562 & -0.148 & ** & 0.331 & -0.216 & $* * *$ & 0.611 \\
\hline $\begin{array}{l}\text { United } \\
\text { Kingdom }\end{array}$ & -0.122 & $* * *$ & 0.557 & -0.105 & $* * *$ & 0.655 & -0.109 & $* * *$ & 0.609 & -0.116 & $* * *$ & 0.631 \\
\hline EU-15 & -0.145 & $* * * *$ & 0.360 & -0.136 & $* * * *$ & 0.412 & -0.093 & 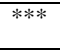 & 0.230 & -0.151 & $* * *$ & 0.422 \\
\hline $\begin{array}{l}\text { Continental } \\
\text { Europe }\end{array}$ & -0.081 & $* * *$ & 0.190 & -0.109 & $* * *$ & 0.312 & -0.021 & & 0.022 & -0.119 & $* * *$ & 0.310 \\
\hline $\begin{array}{l}\text { Nordic } \\
\text { countries }\end{array}$ & -0.194 & $* * *$ & 0.576 & -0.124 & $* * *$ & 0.510 & -0.102 & $* * *$ & 0.233 & -0.149 & $* * *$ & 0.515 \\
\hline $\begin{array}{l}\text { Southern } \\
\text { Europe (PIGS) }\end{array}$ & -0.166 & $* * *$ & 0.542 & -0.147 & $* * *$ & 0.583 & -0.146 & $* * * *$ & 0.582 & -0.157 & $* * *$ & 0.603 \\
\hline $\begin{array}{l}\text { Anglo-Saxon } \\
\text { countries }\end{array}$ & -0.184 & **** & 0.360 & -0.164 & $* * *$ & 0.359 & -0.186 & $* * *$ & 0.449 & -0.180 & $* * *$ & 0.373 \\
\hline
\end{tabular}

Note: ${ }^{* * *} p<0.01,{ }^{* *} p<0.05,{ }^{*} p<0.10$. Continental Europe: Austria, Belgium, France, Germany, Luxembourg, and Netherlands; Nordic countries: Denmark, Finland and Sweden; Southern Europe (PIGS): Portugal, Italy, Greece and Spain; and Anglo-Saxon countries: Ireland and the United Kingdom.

Table3. Okun's Law coefficients: ‘GAP Approach', total population

\begin{tabular}{|c|c|c|c|c|c|c|c|c|c|c|c|c|}
\hline \multirow{3}{*}{ Country } & \multicolumn{9}{|c|}{ Age-cohort (years) } & \multirow{2}{*}{\multicolumn{3}{|c|}{$15-64$ years }} \\
\hline & \multicolumn{3}{|c|}{$15-24$} & \multicolumn{3}{|c|}{$25-54$} & \multicolumn{3}{|c|}{$55-64$} & & & \\
\hline & & & $\mathrm{R}^{2}$ & & & $\mathrm{R}^{2}$ & & & $\mathrm{R}^{2}$ & & & $\mathrm{R}^{2}$ \\
\hline Austria & -0.158 & **** & 0.598 & -0.118 & **** & 0.513 & -0.019 & & 0.060 & -0.125 & & 0.512 \\
\hline Belgium & -0.101 & **** & 0.628 & -0.098 & **** & 0.443 & -0.079 & ** & 0.323 & -0.109 & *** & 0.526 \\
\hline Denmark & -0.111 & $* * *$ & 0.815 & -0.081 & $* * *$ & 0.763 & -0.072 & **** & 0.504 & -0.091 & **** & 0.778 \\
\hline Finland & -0.312 & **** & 0.782 & -0.247 & ***** & 0.781 & -0.191 & & 0.282 & -0.296 & **** & 0.788 \\
\hline
\end{tabular}


INTERDISCIPLINARY APPROACH TO ECONOMICS AND SOCIOLOGY

\begin{tabular}{|c|c|c|c|c|c|c|c|c|c|c|c|c|}
\hline France & -0.145 & **** & 0.680 & -0.088 & *** & 0.343 & -0.078 & **** & 0.464 & -0.109 & **** & 0.462 \\
\hline Germany & -0.089 & & 0.086 & -0.184 & $* *$ & 0.242 & -0.063 & & 0.027 & -0.186 & & 0.216 \\
\hline Greece & -0.256 & ***** & 0.833 & -0.221 & **** & 0.911 & -0.240 & **** & 0.948 & -0.231 & **** & 0.925 \\
\hline Ireland & -0.225 & **** & 0.819 & -0.212 & **** & 0.823 & -0.234 & $* * *$ & 0.882 & -0.221 & **** & 0.823 \\
\hline Italy & -0.137 & ***** & 0.739 & -0.140 & **** & 0.695 & -0.106 & **** & 0.533 & -0.139 & **** & 0.696 \\
\hline Luxembourg & 0.000 & & 0.000 & -0.111 & & 0.104 & 0.019 & & 0.019 & -0.071 & & 0.042 \\
\hline Netherlands & -0.086 & **** & 0.777 & -0.069 & **** & 0.792 & -0.057 & *** & 0.399 & -0.077 & **** & 0.774 \\
\hline Portugal & -0.096 & **** & 0.670 & -0.083 & **** & 0.557 & -0.104 & **** & 0.655 & -0.090 & *** & 0.601 \\
\hline Spain & -0.089 & $* * *$ & 0.436 & -0.079 & $* *$ & 0.431 & -0.104 & $* * *$ & 0.539 & -0.084 & **** & 0.435 \\
\hline Sweden & -0.239 & $* * *$ & 0.823 & -0.171 & $* * *$ & 0.582 & -0.182 & $* * *$ & 0.475 & -0.217 & $* * *$ & 0.749 \\
\hline $\begin{array}{l}\text { United } \\
\text { Kingdom }\end{array}$ & -0.108 & $* * *$ & 0.830 & -0.097 & $* * *$ & 0.862 & -0.119 & $* * *$ & 0.855 & -0.104 & $* * *$ & 0.843 \\
\hline EU-15 & -0.156 & **** & 0.607 & -0.140 & **** & 0.612 & -0.134 & **** & 0.514 & -0.151 & **** & 0.626 \\
\hline $\begin{array}{l}\text { Continental } \\
\text { Europe }\end{array}$ & -0.081 & **** & 0.248 & -0.082 & **** & 0.319 & -0.027 & & 0.050 & -0.089 & **** & 0.304 \\
\hline $\begin{array}{l}\text { Nordic } \\
\text { countries }\end{array}$ & -0.161 & **** & 0.658 & -0.116 & **** & 0.564 & -0.100 & **** & 0.328 & -0.134 & **** & 0.596 \\
\hline $\begin{array}{l}\text { Southern } \\
\text { Europe (PIGS) }\end{array}$ & -0.138 & **** & 0.577 & -0.128 & **** & 0.606 & -0.149 & $* * *$ & 0.677 & -0.135 & **** & 0.624 \\
\hline $\begin{array}{l}\text { Anglo-Saxon } \\
\text { countries }\end{array}$ & -0.201 & **** & 0.775 & -0.186 & *** & 0.773 & -0.213 & $* * *$ & 0.845 & -0.196 & $* * *$ & 0.778 \\
\hline
\end{tabular}

Note: ${ }^{* * *} p<0.01,{ }^{* *} p<0.05,{ }^{*} p<0.10$. Continental Europe: Austria, Belgium, France, Germany, Luxembourg, and Netherlands; Nordic countries: Denmark, Finland and Sweden; Southern Europe (PIGS): Portugal, Italy, Greece and Spain; and Anglo-Saxon countries: Ireland and the United Kingdom.

Firstly, it is noteworthy from these Tables 2 and 3 that coefficients are statistically significant and they have the expected signs according to a priori economic criteria. That is, the empirical analysis shows an inverse relationship between unemployment and output which holds for most of the European countries (Luxembourg is never significant. These results go hand in hand with the R-sq, which is quite low precisely almost always when it is not found significant coefficients) and for the whole sample and subsamples, and so, it could be argued that these estimates are robust and consistent.

Secondly, our results point out that these developed countries included in the EU-15 that constitute our sample, experience smaller output loss associated with higher unemployment in recent years. It is also found smaller values for the oldest age cohort. This fact suggests that the oldest population tends to be less exposed to the business cycles in this selected sample. Meanwhile, regarding elasticities estimates we found slight differences along countries and European macro-areas. E.g. The 15-64 years estimates in average terms are from Denmark and the Netherlands (-0.08) to Finland (-0.30). For macro-areas Continental Europe is at the lower end (-0.08).

Following the same logic, if we focus on the two approaches considered in our empirical analysis, we can highlight the following findings. On the one hand, in spite being very similar results, coefficients are smaller for the 'gap' model. On the other hand, mostly, smaller values (in absolute terms) for the oldest age cohort are found in the different samples, regions or macro-areas considered. Again, it is appreciated that the youngest age cohort plays a key role. E.g. and continuing with a country of the previous example Denmark presents the following elasticities for each of the age-cohorts: $(-0.10),(-0.07 ;-0.08)$, and $(-0.06 ;-0.07)$. 


\section{Conclusion}

From an economic perspective, the unemployment rate understood as unutilized labor capacity, is an important indicator both social and economic dimensions. In this study, our main goal is to test the robustness of the Okun's relationship during the latest decade in EU-15 countries. Besides, the analysis has been done both by individual country and considering four macro-areas: Continental Europe, Nordic countries, Southern Europe (PIGS) and Anglo-Saxon countries. The main hypothesis to be tested was that there is a significantly negative coefficient on cyclical output. Besides, than differences by age and gender could appear.

In spite of the fact that there is vast evidence regarding Okun's Law and compared to recent contributions (Bod'a and Považanová, 2015; or Rahman and Mustafa, 2017), our empirical research analyses the link between unemployment rates changes and real output ones for those developed particular countries, using data in different specifications and several factors, altogether. This topic is particularly relevant for these European countries (EU-15) given the high unemployment rates since the latest economic crisis. Precisely, in the time period studied, unemployment records could be sum as follows. At the beginning of 2005, a period of steadily declining unemployment started, lasting until 2008 when unemployment hit a low before rising sharply in the wake of the economic crisis. Between 2008 and mid-2010 the unemployment level went up to a maximum since the start of the decade. Later, since 2011 and until 2013 unemployment progressively increased. After that, the unemployment rate started to decrease up to date (Eurostat, 2016).

The hypothesis results show an inverse relationship in Europe between unemployment and GDP. Nevertheless, slight differences among countries and macro-areas are found (not in the sign, just in the values). Overall, our empirical findings have highlighted that European developed countries experience smaller output loss associated with higher unemployment (Ollivaud and Turner, 2015). Results in this sample also corroborate the elder the population, the less exposed to the business cycles. However, unexpectedly, younger unemployment does not appear to be more susceptible to cyclical economic changes than overall unemployment (Bredemeier and Winkler, 2017).

In general, the reported findings have some usefulness for productivity growth in developed countries and it must be considered in policies strategies. In fact, in spite being unemployment rates (and levels) largely related to the general business cycle, other factors such as labor and demographic developments could influence both, their short and long-term evolution. At this regard, Huang and Yeh (2013) confirmed both, the validity of Okun's Law (in the short-run) but also points out that a similar trade-off exists in the long-run.

We did not directly account for the instability of the Okun's Law coefficients following the economic and financial crisis, mainly due to the sample size, but is known that several EU countries introduce age-specific labor market regulations. However, the current reformed agenda is too narrowly specified in spite the fact that the general aims are clear (Rubery and Piasna, 2016). Reforms are also targeted to older people such as changes in the hiring and firing regulations. Besides, intensity and effectiveness of labor market regulation differ among areas (Imbens and Lynch, 2006) as the policymakers do not have coordinated strategies (Barbieri and Cutuli, 2015).

As disparities in productivity growth are shown in our results, different policies are then needed in each country or macro-area here considered. Indeed, policymakers should face this challenge by designing several ways to increase employment opportunities for diverse groups in society, e.g.: those on specific age cohorts (as the youngest), those working in particular economic activities (Şahin et al., 2015), or more precisely, those living in specific countries or macro-regions (specific coordinated policies for each necessity). Moreover, different initiatives 
should be considered including proposals aimed at education and training institutions.in this regard, Khalifa (2013) provide a plausible explanation for unemployment persistence and the cyclical pattern of the skill premium. In short, the relationship between macroeconomic performance and institutional change should be explored as was done by Welsch and Kühling (2016).

Future research could be improved when considering the full sample of European countries and a longer period of time. Besides to consider unemployment rates by other characteristics like dissimilarities between foreigners vs. national, different educational levels, etc. When more data would be available, this extension should be considered as there are issues of this interesting relationship that remain unexplained.

\section{References}

Albanesi, S., \& Sahin, A. (2013). The gender unemployment gap. FRB of New York Staff Report 613.

Attfield, C. L., \& Silverstone, B. (1997). Okun's coefficient: a comment. The Review of Economics and Statistics, 79(2), 326-329.

Ball, L. M., Leigh, D., \& Loungani, P. (2013). Okun's law: fit at fifty? (No. w18668). National Bureau of Economic Research.

Bande, R., \& Martín-Román, Á. L. (2017). Regional differences in the Okun's Relationship: New Evidence for Spain (1980-2015). Working Paper 79833. MPRA.

Barbieri, P., \& Cutuli, G. (2015). Employment protection legislation, labor market dualism, and inequality in Europe. European Sociological Review, 32(4), 501-516.

Bredemeier, C., \& Winkler, R. (2017). The employment dynamics of different population groups over the business cycle. Applied Economics, 49(26), 2545-2562.

Bod'a, M., \& Považanová, M. (2015). Gender Asymmetry in Okun's Law in the Four PIGS Countries. Procedia Economics and Finance, 30, 111-123.

Cuaresma, J. C. (2003). Okun's law revisited. Oxford Bulletin of Economics and Statistics, $65(4), 439-451$.

De Jong, R. M., \& Sakarya, N. (2016). The econometrics of the Hodrick-Prescott filter. Review of Economics and Statistics, 98(2), 310-317.

Economou, A., \& Psarianos, I. N. (2016). Revisiting Okun's Law in European Union countries. Journal of Economic Studies, 43(2), 275-287.

Eurostat (2016). http://ec.europa.eu/eurostat/data/database.

Hamia, M. A. A. (2016). Jobless growth: empirical evidence from the Middle East and North Africa region. Journal for Labour Market Research, 49(3), 239-251.

Huang, H. C., \& Yeh, C. C. (2013). Okun's law in panels of countries and states. Applied Economics, 45(2), 191-199.

Hutengs, O., \& Stadtmann, G. (2013). Age effects in Okun's law within the Eurozone. Applied Economics Letters, 20(9), 821-825.

Imbens, G. W., \& Lynch, L. M. (2006). Re-employment probabilities over the business cycle. Portuguese Economic Journal, 5(2), 111-134.

Kargi, B. (2016). Okun's Law and Long-Term Co-Integration Analysis for OECD Countries (1987-2012). Emerging Markets Journal, 6(1), 39-46.

Khalifa, S. (2013). Cyclical job upgrading, wage inequality, and unemployment dynamics. International Economic Journal, 27(4), 549-585.

Lee, J. (2000). The robustness of Okun's law: Evidence from OECD countries. Journal of Macroeconomics, 22(2), 331-356.

Malley, J., \& Molana, H. (2008). Output, unemployment and Okun's law: Some evidence from 
the G7. Economics Letters, 101(2), 113-115.

Melguizo, C. (2017). An analysis of Okun's law for the Spanish provinces. Review of Regional Research, 37(1), 59-90.

Micallef, B. (2016). Empirical estimates of Okun's Law in Malta. Applied Economics and Finance, 4(1), 138-148.

Moazzami, B., \& Dadgostar, B. (2011). Okun's Law Revisited: Evidence From OECD Countries. International Business \& Economics Research Journal (IBER), 8(8), 21-24.

Moosa, I. A. (1997). A cross-country comparison of Okun's coefficient. Journal of comparative economics, 24(3), 335-356.

Mundlak, Y. (1978). On the pooling of time series and cross-section data. Econometrica: Journal of the Econometric Society, 69-85.

OECD Statistics (2017). http://stats.oecd.org/

Okun, A. Potential GnP: Its measurement and significance. Proceedings, Business, and Economic Statistics Section (American Statistical Association, 1962), pp. 98-104.

Okun, A. M. (1970). The political economy of prosperity. Brookings Inst Pr.

Ollivaud, P., \& Turner, D. (2015). The effect of the global financial crisis on OECD potential output. OECD Journal: Economic Studies, 2014(1), 41-60.

Palombi, S., Perman, R., \& Tavéra, C. (2017). Commuting effects in Okun's Law among British areas: Evidence from spatial panel econometrics. Papers in Regional Science, 96(1), 191209.

Perman, R., Stephan, G., \& Tavéra, C. (2015). Okun's Law - a Meta- analysis. The Manchester School, 83(1), 101-126.

Rahman, M., \& Mustafa, M. (2017). Okun's law: evidence of 13 selected developed countries. Journal of Economics and Finance, 41(2), 297-310.

Rubery, J., \& Piasna, A. (2016). Labour market segmentation and the EU reform agenda: developing alternatives to the mainstream. Working Paper 10. ETUI.

Rudawska, I. (2010). Active aging and its impact on the labor market. Economics and Sociology, 3(1), 9-24.

Şahin, A., Tansel, A., \& Berument, M. H. (2015). Output-Employment Relationship across Sectors: A Long- Versus Short- Run Perspective. Bulletin of Economic Research, 67(3), 265-288.

Silvapulle, P., Moosa, I. A., \& Silvapulle, M. J. (2004). Asymmetry in Okun's law. Canadian Journal of Economics/Revue Canadienne'économique, 37(2), 353-374.

Villaverde, J., \& Maza, A. (2009). The robustness of Okun's law in Spain, 1980-2004: Regional evidence. Journal of Policy Modelling, 31(2), 289-297.

Weber, C. E. (1995). Cyclical output, cyclical unemployment, and Okun's coefficient: A new approach. Journal of applied econometrics, 10(4), 433-445.

Welsch, H., \& Kühling, J. (2016). Macroeconomic performance and institutional change: Evidence from subjective well-being data. Journal of Applied Economics, 19(2), 193217.

Zanin, L. (2014). On Okun's law in OECD countries: an analysis by age cohorts. Economics Letters, 125(2), 243-248.

Zanin, L., \& Marra, G. (2012). Rolling regression versus time- varying coefficient modeling: an empirical investigation of the Okun's law in some Euro area countries. Bulletin of Economic Research, 64(1), 91-108.

Zanin, L. (2016). The pyramid of Okun's coefficient for Italy. Empirical, 1-12. 


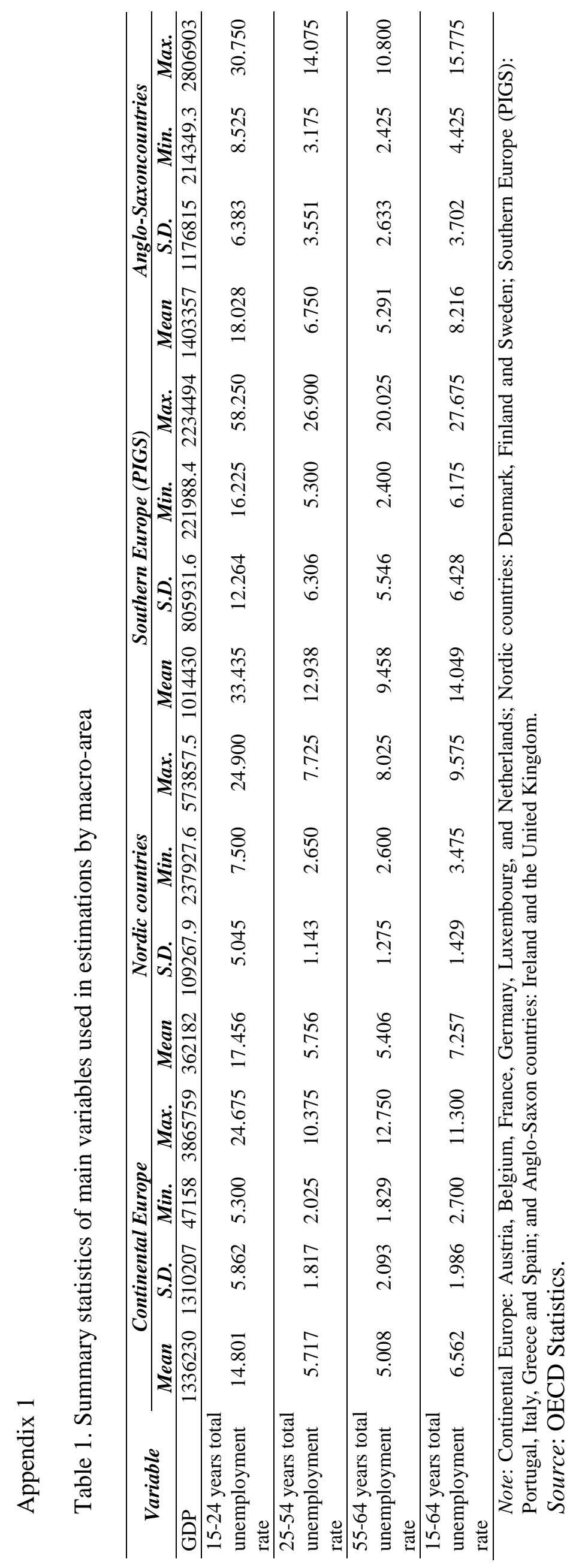

